\title{
The prevalence and determinants of use of vitamin $D$ supplements among children in Alberta, Canada: a cross-sectional study
}

\author{
Lalani L. Munasinghe ${ }^{1}$, Noreen Willows ${ }^{2}$, Yan Yuan $^{3}$ and Paul J. Veugelers ${ }^{1 *}$
}

\begin{abstract}
Background: Limited cutaneous synthesis due to low sun exposure and inadequate dietary intake makes vitamin D supplementation a necessity for many Canadian children. Identification of the factors associated with supplement use is necessary for public health awareness campaigns, but they have not been identified previously. Therefore, the purpose of this study was to assess the prevalence and the determinants of the use of vitamin D supplements among children in the province of Alberta, Canada.
\end{abstract}

Methods: In 2014, a representative sample of grade five students (10-11 y) in Alberta $(n=2686)$ was surveyed. Data on dietary intake and use of vitamin D supplements were obtained using a modified Harvard Youth/Adolescent Food Frequency questionnaire. Mixed effect multiple logistic regression was employed to identify the key correlates of supplement use.

Results: Use of vitamin D supplements by children was $29.45 \%$ although only $11.83 \%$ took supplements daily. Children who resided in a metropolitan area $(\mathrm{OR}=1.32 ; 95 \% \mathrm{Cl}: 1.06-1.65)$, were more physically active (2nd tertile: $\mathrm{OR}=1.39 ; 95 \% \mathrm{Cl}: 1.09-1.78$ and 3rd tertile: $\mathrm{OR}=1.70 ; 95 \% \mathrm{Cl}: 1.33-2.16)$, or whose parents completed college $(\mathrm{OR}=1.35 ; 95 \% \mathrm{Cl}: 1.05-1.74)$ were more likely to take vitamin D supplements. Prevalence of use was highest among those who had a high vitamin D diet and those with under/normal body weight status, although supplement use was not statistically associated with either dietary vitamin D intake or weight status.

Conclusions: A considerable proportion of children did not take vitamin D supplements. Region of residence, physical activity level and parental education were determinants of supplement use, independent of child's gender, household income, weight status and dietary practices. We suggest prioritizing public health efforts to support strategies to make parents aware of the importance of providing the correct dose of vitamin D supplements for their children to meet dietary recommendations.

Keywords: Vitamin D, Children, Supplements, Multivitamins, Public health, Determinants

\section{Background}

The 2012/2013 Canadian Health Measure Survey [1] revealed that $35 \%$ of all Canadians and more than $20 \%$ of children are at risk of poor bone health. This is presumably due to limited cutaneous synthesis of vitamin D through sun exposure because of Canada's high latitude $[2,3]$ and poor dietary intake of vitamin D rich foods [3-6]. Obese and overweight children are potentially

\footnotetext{
* Correspondence: paul.veugelers@ualberta.ca

'School of Public Health, University of Alberta, Population Health Intervention Research Unit, 3-50 University Terrace, 8303112 Street, Edmonton, AB T6G2T4, Canada

Full list of author information is available at the end of the article
}

more susceptible for poor vitamin D status $[1,7]$ because of sequestration of vitamin D into a larger pool of adipose tissues in the body $[8,9]$. Efficacy of the mandatory vitamin $\mathrm{D}$ fortification of designated staple foods in Canada $[10,11]$ to ensure vitamin D adequacy is low due to under-fortification [12] and insufficient consumption $[4,12]$. Therefore, meeting current dietary guidelines for vitamin D that includes an estimated average requirement of $400 \mathrm{IU} /$ day and a recommended dietary allowance of $600 \mathrm{IU} /$ day for children over 1 year of age [13] is difficult without supplementation. Canadians who use supplements are more likely to maintain 
adequate vitamin D levels [7, 14]. Studies [2, 6, 14-16] have emphasized the importance of supplementation as a strategy to overcome the issue of poor vitamin $\mathrm{D}$ status. Although all Canadians might benefit from supplements to maintain vitamin D levels [14], Health Canada [17] only recommends a daily vitamin D supplement of $400 \mathrm{IU}$ for breastfed, healthy term infants and adults over the age of 50. There are no recommendations for the vitamin $\mathrm{D}$ supplementation of children.

Studies have identified age $[18,19]$, gender [20], weight status [21], socio-economic status [19,21], level of physical activity [20-23], quality of diet [21, 22], and parental use of supplements [18] to be associated with the use of multivitamin/mineral supplements among children. Although the factors associated with multivitamin/mineral supplement use are well studied, those associated with vitamin D supplement use among children have not been given attention. In Canada, vitamin D supplements for children are available as vitamin D supplements (containing only vitamin D) and vitamin D-containing multivitamins. However, it is advisable to use vitamin D supplements as cholecalciferol to meet dietary guidelines due to the varying forms of vitamin D (i.e., ergocalciferol and cholecalciferol) and amount of vitamin D in multivitamins. Given that the determinants of use can vary according to the type of supplement being considered [24], the factors associated with the use of vitamin D supplements need to be studied. Awareness of such factors is crucial to inform policy decision-makers and stakeholders in planning programs to promote the optimal vitamin D status of the population through supplementation. The purpose of this study was to determine the prevalence of vitamin D supplement use and the associated factors among children in Alberta. Unlike use of vitamin D supplements, the use of multivitamins is quite common among developed nations $[19,23,24]$. Therefore, we also aimed to identify if there were differences in the factors associated with vitamin D supplement use with those of multivitamin/mineral use. This information would be valuable in establishing whether programs for promoting vitamin $\mathrm{D}$ use would need to be different from programs promoting supplement use in general.

\section{Methods}

\section{The survey and subjects}

We analyzed data on demographic and socio-economic factors, diet and supplements, and physical activity that were collected as part of the "Raising healthy Eating and Active Living Kids in Alberta" (REAL Kids Alberta) survey, a population-based study of grade five students (age 10-11 years) and their parents in the province of Alberta, Canada in 2014. A one-stage stratified random sample of 140 elementary schools across Alberta was selected. The sampling frame included all elementary schools in Alberta with grade five students with the exception of private schools, francophone schools, on-reserve federal schools, charter schools and colony schools. Therefore, $90.2 \%$ of all elementary students in Alberta were eligible for random selection based on three geographical strata (metropolitan, urban, and rural). Schools were randomly selected within each stratum to achieve proportional representation [25]. More details on the project aim and the measures used are available on the project's website: http://www. realkidsalberta.ca. A total of 4993 home booklets and parental consent forms were sent home with students to be completed by parent(s) or guardian(s) and returned to school. Among 3284 booklets returned, 2958 students were granted consent and participated in the study (participation rate $=59 \%$ ). Students who did not complete the food frequency questionnaires $(n=107)$ and 46 with missing data on use of multivitamins and/or vitamin D supplements were excluded from the present analysis. Students who had reported energy intakes of $<500 \mathrm{kcal}$ and $>5000 \mathrm{kcal}$ were excluded $(n=119)$ as per established criteria when food frequency questionnaire data is involved [26]. Therefore, the analysis of the present study was restricted to a total of 2686 students (53.8 \%).

\section{Outcome of interest: vitamin D-containing supplement use} Information on use of vitamin D supplements and multivitamins was obtained from a modified Harvard Youth/ Adolescent Food Frequency Questionnaire (YAQ). Under the guidance of a trained evaluation assistant, each student completed the YAQ during classroom time in a school day. In separate questions, students were asked, "Do you now take vitamin D supplements (pills/drops)?", "Do you now take multivitamins?", "How often did you take vitamin D supplements over the past year?" and "How often did you take multivitamins over the past year?". "Vitamin D supplement users" were defined as a child who reported ever taking a vitamin D supplement and "multivitamin supplement users" a child who reported ever taking a multivitamin.

\section{Anthropometric, demographic, socio-economic, and lifestyle determinants}

Evaluation assistants measured weight and standing height from all children to calculate Body Mass Index (BMI) as weight divided by height ${ }^{2}\left(\mathrm{~kg} / \mathrm{m}^{2}\right)$. Weight was measured to the nearest $0.1 \mathrm{~kg}$ using calibrated digital scales (Health-o-meter, USA) and height was measured to the nearest $0.1 \mathrm{~cm}$ using stadiometers (Seca-Stadiometers, Germany). Overweight and obesity were defined according to the age- and gender- specific cut-offs of the International Obesity Task Force BMI for children and youth [27]. Region of residence was defined based on the schools located in three geographical locations: metropolitan (Calgary and Edmonton, cities with a population of about 
1 million people each), urban (other municipalities with more than 40,000 residents) and rural (municipalities with less than 40,000 residents). Data on the level of parent education attainment and household income were collected from parent responses in the home survey. Physical activity level (PAL) was identified as a single physical activity score ranging from 0 to 5 that was derived from a 29-item questionnaire adapted from the Physical Activity Questionnaire for Older Children (PAQ-C), which has been validated for children [28]. The physical activity questionnaire contains questions about active transportation, activity level inside and outside of school hours, participation in sports and other forms of active play. Diet quality was derived using the Diet Quality Index International, a composite measure that encompasses dietary adequacy, variety, moderation, and balance ranging from 0 to 100 [29]. Dietary intake data were obtained based on responses to the questions in validated YAQ [30] that assesses diets of those 9-18 years of age. Total dietary vitamin D intake and total calorie intake from food were calculated using Canadian Nutrient File [31].

\section{Statistical analyses}

Data were analyzed using Stata version 13 (Stata Corp, College Station, TX, USA). Descriptive statistics were used to characterize the population and to identify the frequencies of children using vitamin D supplements and multivitamins. Mixed effect multiple logistic regression models with children nested in schools identified the association of weight status, lifestyle, socioeconomic, and demographic factors with use of vitamin D supplements and multivitamins. Akaike Information Criteria and Bayesian Information Criteria were employed to select the parsimonious multiple regression models. Missing data were treated as a separate category. Data analyses were adjusted for total energy intake when food frequency data were involved as per established criteria [26]. All analyses were weighted to represent unbiased provincial estimates of the grade five student population in Alberta. The Health Research Ethics Board at the University of Alberta approved this study, including data collection and parental informed consent forms.

\section{Results}

Altogether, $62.14 \%$ of grade five students (age 10-11 years) in Alberta participating in this study took only vitamin D supplement (8.06 \%), only multivitamin (32.69\%), or both a vitamin $\mathrm{D}$ supplement and multivitamin $(21.39 \%)$. The characteristics of students taking vitamin D supplements $(29.45 \%)$ and multivitamins $(54.08 \%)$ are presented in Table 1 . However, of grade five students, only 11.83 \% took vitamin D supplements and $28.43 \%$ took multivitamins on a daily basis during the past year.
Table 2 depicts the associations of demographic, socioeconomic, anthropometric and life style factors on the use of vitamin D supplements. Students whose parents completed education up to college level were more likely to take vitamin D supplements as compared to those whose parents completed secondary school education or less (univariable: $\mathrm{OR}=1.38$; $95 \% \mathrm{CI}=1.06,1.78$ and parsimonious: $\mathrm{OR}=1.35 ; 95 \% \mathrm{CI}=1.05,1.74)$. Students residing in a metropolitan area were more likely to take vitamin $\mathrm{D}$ supplement as compared to those attending schools in rural areas (univariable: $\mathrm{OR}=1.27 ; 95 \% \mathrm{CI}=$ 1.03, 1.56 and parsimonious: $\mathrm{OR}=1.32 ; 95 \% \mathrm{CI}=1.06$, 1.65). PAL was highly correlated with vitamin $D$ supplement use in both univariable (1st Tertile: $\mathrm{OR}=1.39$; $95 \% \mathrm{CI}=1.09,1.77$ and 2 nd Tertile: $\mathrm{OR}=1.68 ; 95 \% \mathrm{CI}=$ $1.33,2.14$ ) and parsimonius (1st Tertile: $\mathrm{OR}=1.39$; $95 \% \mathrm{CI}=1.09,1.78$ and 2nd Tertile: $\mathrm{OR}=1.70 ; 95 \% \mathrm{CI}=$ 1.33, 2.16) models. Table 3 shows that parental education, household income and PAL were associated with multivitamin use. Energy-adjusted dietary vitamin D intake was not retained in the parsimonious models for either type of supplement (vitamin D supplement in Table 2 or multivitamin in Table 3).

\section{Discussion}

This study indicated that approximately one third of school children aged 10-11 years in Alberta took vitamin D supplements and approximately half of them took multivitamins. Parental education, region of residence and PAL were determinants of vitamin D supplement use among children, independent of child's gender, household income, weight status and dietary practices. Both vitamin $\mathrm{D}$ and multivitamin supplement use were more prevalent among physically active children and those from families with high socioeconomic status, and use was less common among boys than among girls.

Consistent with other findings [19, 23, 24], we identified that children in Alberta were more likely to use multivitamins than vitamin D supplements. Although the use of supplements (vitamin D supplements, multivitamins, or both) was twice as common among children in our study (62\%) compared to the national averages in 2007/2009 of $31 \%$ [32] and in 2009/2011 of $34 \%$ [7], only small proportions of children were taking supplements once a day, or more frequently. Therefore, promotion of supplements on a daily basis is essential to meet the recommended daily requirement of vitamin $\mathrm{D}$.

Parental education was associated with use of both vitamin D supplements and multivitamins. We did not find any association of vitamin D supplement use with household income, whereas multivitamin use in our study and other studies $[11,19,21]$ had a positive association with income. Therefore, unlike multivitamin use, vitamin D supplement use mainly depended on the knowledge of 
Table 1 General characteristics and the prevalence of supplement use of 10-11 year-old students in Alberta, Canada

\begin{tabular}{|c|c|c|c|}
\hline & All students, $\%^{\mathrm{a}}(n=2686)$ & $\begin{array}{l}\text { Vitamin D supplement users (with or } \\
\text { without multivitamin use), } \%(n=769)^{a}\end{array}$ & $\begin{array}{l}\text { Multivitamin supplement users (with or without } \\
\text { vitamin D supplement use), } \%(n=1468)\end{array}$ \\
\hline \multicolumn{4}{|l|}{ Gender } \\
\hline Girls & 53.49 & 51.81 & 54.57 \\
\hline Boys & 46.51 & 48.19 & 45.43 \\
\hline \multicolumn{4}{|l|}{ Parental education ${ }^{b}$} \\
\hline Secondary or less & 23.19 & 19.68 & 21.07 \\
\hline College & 33.54 & 35.87 & 34.28 \\
\hline University/graduate & 37.89 & 38.90 & 39.99 \\
\hline \multicolumn{4}{|l|}{ Household income } \\
\hline$\leq \$ 50,000$ & 13.21 & 12.82 & 11.55 \\
\hline$\$ 50,001-\$ 100,000$ & 19.03 & 19.64 & 20.09 \\
\hline$\geq \$ 100,001$ & 28.89 & 30.07 & 30.81 \\
\hline Non-disclosed/Missing ${ }^{c}$ & 38.87 & 37.48 & 37.55 \\
\hline \multicolumn{4}{|l|}{ Region of residence } \\
\hline Rural & 39.55 & 35.87 & 40.19 \\
\hline Urban & 8.28 & 8.14 & 8.65 \\
\hline Metropolitan & 52.17 & 55.99 & 51.16 \\
\hline \multicolumn{4}{|l|}{ Weight status $^{\mathrm{b}}$} \\
\hline Under/normal weight & 68.59 & 71.30 & 70.55 \\
\hline Overweight & 20.84 & 18.38 & 19.61 \\
\hline Obese & 7.86 & 7.58 & 6.76 \\
\hline \multicolumn{4}{|l|}{ Physical activity level } \\
\hline 1st Tertile & 33.32 & 27.85 & 30.94 \\
\hline 2nd Tertile & 33.32 & 34.11 & 32.97 \\
\hline 3rd Tertile & 33.36 & 38.04 & 36.09 \\
\hline \multicolumn{4}{|c|}{ Energy-adjusted diet quality index ${ }^{d}$} \\
\hline 1st Tertile & 33.32 & 30.76 & 31.09 \\
\hline 2nd Tertile & 33.32 & 34.43 & 34.37 \\
\hline 3rd Tertile & 33.36 & 34.81 & 34.54 \\
\hline \multicolumn{4}{|c|}{ Energy-adjusted total dietary vitamin $\mathrm{D}^{\mathrm{d}}$} \\
\hline 1st Tertile & 33.32 & 33.73 & 32.77 \\
\hline 2nd Tertile & 33.32 & 31.76 & 31.64 \\
\hline 3rd Tertile & 33.36 & 34.51 & 35.59 \\
\hline
\end{tabular}

${ }^{a}$ Results were weighted to represent provincial estimates of the grade five student population (age: 10-11y) in Alberta

${ }^{b}<5 \%$ of missing data

${ }^{c} 26.63 \%$ non-disclosed responses (participants were provided option not to disclose their household income) and $12.23 \%$ missing data

d"Energy adjusted" DQI and dietary vitamin D intake were computed as the residuals from the regression model with total energy intake as the independent variable and absolute DQI or dietary vitamin D intake as the dependent variable as per established criteria [26]

the parents, independent of their income. Students residing in a metropolitan area were more likely to take vitamin D supplements than those attending schools in rural area. However, residential area was not associated with multivitamin supplement use, and most of the multivitamins available for children in Canada contain only half of the recommended daily amount of vitamin D. Parents may have been unaware of the vitamin $\mathrm{D}$ composition in multivitamins or the importance of vitamin $\mathrm{D}$ for their children.
Therefore, dissemination of public health knowledge on children's need for sole vitamin D supplements based on residential area appears to be important.

Vitamin D status of Canadians mainly depends on the diet and supplements [33] due to limited cutaneous synthesis [2, 3]. Among children in Alberta, the prevalence of both vitamin D supplement and multivitamin use were low among those who consumed less vitamin $\mathrm{D}$ from the diet (30-35\% in each tertile); therefore 
Table 2 Determinants of vitamin D supplement use among 10-11-year-old students in Alberta, Canada ${ }^{a}$

\begin{tabular}{lll}
\hline Univariable model & Parsimonious model \\
& Odds ratio $(95 \% \mathrm{Cl})$ & Odds ratio $(95 \% \mathrm{Cl})$ \\
\hline
\end{tabular}

Demographic, socio-economic and anthropometric factors

Gender

Girls

1.00

1.00

Boys

$1.10(0.91,1.33)$

$1.03(0.85,1.25)$

Parental education

$\begin{array}{lll}\text { Secondary or less } & 1.00 & 1.00 \\ \text { College } & 1.38(1.06,1.78)^{*} & 1.35(1.05,1.74)^{*} \\ \text { University or graduate } & 1.29(1.00,1.65)^{*} & 1.21(0.94,1.56)\end{array}$

Household income ${ }^{c}$

$\begin{array}{lll}\leq \$ 50,000 & 1.00 & 1.00 \\ \$ 50,001-100,000 & 1.08(0.80,1.47) & 1.08(0.79,1.48) \\ \geq \$ 100,001 & 1.08(0.80,1.48) & 1.03(0.74,1.43)\end{array}$

Region of residence

$\begin{array}{lll}\text { Rural } & 1.00 & 1.00 \\ \text { Urban } & 1.11(0.91,1.37) & 1.13(0.921 .40) \\ \text { Metropolitan } & 1.27(1.03,1.56)^{*} & 1.32(1.06,1.65)^{*}\end{array}$

Weight status

$\begin{array}{lll}\text { Under/normal weight } & 1.00 & 1.00 \\ \text { Overweight } & 0.80(0.64,1.00)^{*} & 0.82(0.66,1.04) \\ \text { Obese } & 0.91(0.60,1.40) & 0.93(0.60,1.43)\end{array}$

Lifestyle factors

Physical activity level

$\begin{array}{lll}\text { 1st Tertile } & 1.00 & 1.00 \\ \text { 2nd Tertile } & 1.39(1.09,1.77)^{* *} & 1.39(1.09,1.78)^{* *} \\ \text { 3rd Tertile } & 1.68(1.33,2.14)^{* * *} & 1.70(1.33,2.16)^{* * *}\end{array}$

Energy-adjusted diet quality index ${ }^{\mathrm{d}}$

$\begin{array}{lll}\text { 1st Tertile } & 1.00 & 1.00 \\ \text { 2nd Tertile } & 1.16(0.91,1.47) & 1.12(0.89,1.42) \\ \text { 3rd Tertile } & 1.18(0.95,1.46) & 1.10(0.89,1.36)\end{array}$

Energy-adjusted dietary vitamin D intake

$\begin{array}{ll}\text { 1st Tertile } & 1.00 \\ \text { 2nd Tertile } & 0.93(0.73,1.19) \\ \text { 3rd Tertile } & 1.03(0.81,1.31)\end{array}$

${ }^{\mathrm{a}}$ Results were weighted to represent provincial estimates of the grade five student population (age: 10-11y) in Alberta. Vitamin D supplement users were defined as those who used vitamin D supplements irrespective of use of multivitamins

${ }^{\mathrm{b}}$ Adjusted for demographic, socio-economic and anthropometric factors in the table

${ }^{{ }^{2}} 26.63 \%$ non-disclosed responses (participants were provided option not to disclose their household income) and $12.23 \%$ missing data

d"Energy adjusted" DQI and dietary vitamin D intake were computed as the residuals from the regression model with total energy intake as the independent variable and absolute DQI or dietary vitamin D intake as the dependent variable as per established criteria [26] ${ }^{*} p<0.05$

*** $p<0.01$

${ }^{* * *} p<0.001$
Table 3 Determinants of use of multivitamins among of 10-11-year-old students in Alberta, Canada ${ }^{a}$

\begin{tabular}{ll}
\hline Univariable model & Parsimonious model \\
Odds ratio $(95 \% \mathrm{Cl})$ & Odds ratio $(95 \% \mathrm{Cl})$ \\
\hline
\end{tabular}

Demographic, socio-economic and anthropometric factors

Gender

$\begin{array}{lll}\text { Girls } & 1.00 & 1.00 \\ \text { Boys } & 0.91(0.75,1.10) & 0.85(0.70,1.03)\end{array}$

Parental education

$\begin{array}{lll}\text { Secondary or less } & 1.00 & 1.00 \\ \text { College } & 1.26(1.02,1.55)^{*} & 1.25(1.02,1.54)^{*} \\ \text { University or graduate } & 1.34(1.07,1.69)^{*} & 1.33(1.06,1.68)^{*}\end{array}$

Household income ${ }^{c}$

$\begin{array}{lll}\leq \$ 50,000 & 1.00 & 1.00 \\ \$ 50,001-100,000 & 1.48(1.10,2.00)^{* *} & 1.43(1.05,1.94)^{*} \\ \geq \$ 100,001 & 1.44(1.09,1.91)^{* *} & 1.29(0.97,1.71)\end{array}$

Region of residence

$\begin{array}{lll}\text { Rural } & 1.00 & 1.00 \\ \text { Urban } & 1.06(0.81,1.40) & 1.06(0.811 .39) \\ \text { Metropolitan } & 0.92(0.73,1.17) & 0.95(0.76,1.19)\end{array}$

Weight status

$\begin{array}{lll}\text { Under/normal weight } & 1.00 & 1.00 \\ \text { Overweight } & 0.84(0.67,1.05) & 0.88(0.70,1.09) \\ \text { Obese } & 0.70(0.50,0.98)^{*} & 0.76(0.54,1.08)\end{array}$

Lifestyle factors

Physical activity level

$\begin{array}{lll}\text { 1st Tertile } & 1.00 & 1.00 \\ \text { 2nd Tertile } & 1.21(0.99,1.47) & 1.20(0.97,1.47) \\ \text { 3rd Tertile } & 1.55(1.26,1.90)^{* * *} & 1.56(1.27,1.91)^{* * *}\end{array}$

Energy-adjusted diet quality index ${ }^{d}$

$\begin{array}{lll}\text { 1st Tertile } & 1.00 & 1.00 \\ \text { 2nd Tertile } & 1.22(0.99,1.51) & 1.20(0.97,1.49) \\ \text { 3rd Tertile } & 1.22(0.97,1.55) & 1.13(0.90,1.43)\end{array}$

Energy-adjusted dietary vitamin D intake ${ }^{\mathrm{d}}$

$\begin{array}{ll}\text { 1st Tertile } & 1.00 \\ \text { 2nd Tertile } & 0.95(0.77,1.17) \\ \text { 3rd Tertile } & 1.16(0.97,1.39)\end{array}$

${ }^{a}$ Results were weighted to represent provincial estimates of the grade five student population (age: 10-11y) in Alberta. Multivitamin users were defined as those who used multivitamins irrespective of use of vitamin D supplements ${ }^{\mathrm{b}}$ Adjusted for demographic, socio-economic and anthropometric factors in the table

${ }^{\mathrm{c}} 26.63 \%$ non-disclosed responses (participants were provided option not to disclose their household income) and $12.23 \%$ missing data d“Energy adjusted" DQI and dietary vitamin D intake were computed as the residuals from the regression model with total energy intake as the independent variable and absolute DQI or dietary vitamin D intake as the dependent variable as per established criteria [26]

${ }^{*} p<0.05$

$* * p<0.01$

*** $p<0.001$ 
approximately $65-70 \%$ of the children with a low intake of dietary vitamin $\mathrm{D}$ were at risk of deficiency. However, we did not find any significant association in the regression analysis of dietary vitamin D intake and quality of the diet with supplement use. Some other findings on multivitamin supplement use [21, 22] demonstrated that children with better quality diets were more likely to take either vitamin D or multivitamin supplements. We previously identified that only onefifth of the students in our study met dietary guidelines for vitamin D through both diet and supplements [34]. Although it is important to encourage children to adopt healthy eating behaviours in addition to taking supplements for adequate nutrient intake [22], our findings reveal the importance of using vitamin D supplements independent of diet quality. Public health strategies aimed at improving the use of vitamin D supplements need to make parents also aware of the importance of consuming vitamin $\mathrm{D}$ rich dietary sources.

Valtueña et al. [35] identified the interactions between vitamin D and PAL in two possible directions, i.e., sufficient vitamin $\mathrm{D}$ levels improve bone health only in active children or PAL improves bone health in individuals with sufficient vitamin D levels. Therefore, predominant use of vitamin D supplements by more active children in our study is notably interesting as proper vitamin D levels potentially better benefit the active children. Obese and overweight children may need extra vitamin $D$ [36] to compensate for their additional requirements. They are susceptible to poor vitamin D status as a result of adipose tissue sequestration $[1,7]$. However, the use of vitamin D supplements and multivitamins was less common among overweight and obese children in the present study. Specifically, overweight children were the least likely to use vitamin $\mathrm{D}$ supplements and obese children were the least likely to use multivitamins. This association was obtained only in the unadjusted models, indicating that the relationship was confounded by demographic, socioeconomic and lifestyle factors. It is not surprising that we did not see any difference in vitamin $\mathrm{D}$ containing supplement use by weight status. The public is likely to be unaware that overweight and obese children need more vitamin $\mathrm{D}$ relative to a normal weight child [36]. The additional requirements for those above healthy body weight need to be considered when recommending supplements and more research is needed to establish weight-specific clinical guidelines for vitamin $\mathrm{D}$.

To our knowledge, this is the first population-based study that describes factors associated with the use of vitamin D supplements among children in Canada. Also, only a few studies have examined the determinants of multivitamin supplement use among children. The other strengths of this study were the use of a large provincially representative sample, its high response rate for school- based research, and, the execution of multilevel regression to account for hierarchical data structure and to assist the survey design effect with weighted analysis. There were some limitations of this study. The use of self-reported information was not validated, but, potential bias was minimized by using a validated food frequency questionnaire that has been shown to be comparable in estimating typical intake to multiple 24-hour recalls. Parents did not answer the question about child supplement use and therefore, it is possible that the children may not have known the difference between vitamin D supplements and multivitamins mentioned in the questionnaire in addition to recall bias. However, evaluation assistants helped minimize this issue by providing explanations while children completed the surveys. The present study was conducted using a sample of grade five students in Alberta and the participation rate was $59 \%$. Therefore, caution is warranted when generalizing results to other children.

\section{Conclusions}

A low proportion of school-aged children were taking vitamin D supplements and most of them did not use them on a daily basis. Physically active children were more likely to use supplements and therefore, parents who encourage their children to be more active may also be more likely to provide them with supplements, or those who were using supplements are more likely to be physically active. Parents with low educational attainment and those who live in rural and urban areas should be the target of campaigns to promote vitamin D supplementation for children. Although overweight and obese children require more vitamin D, vitamin D supplement use was not associated with body weight status. Therefore, nutritionists and health care providers need to consider the weight status of the child when recommending supplements. Therefore, nutritionists and health care providers need to consider the weight status of the child when recommending supplements. Further studies are required to explore other possible determinants of supplement use such as parents' perceptions on using supplements and family history of supplements use.

\section{Abbreviations}

REAL Kids Alberta: Raising healthy eating and active living kids; YAQ: Harvard youth/adolescent food frequency questionnaire; BMI: Body mass index; PAL: Physical activity level.

\section{Competing interests}

The authors declare that they have no competing interests.

\section{Authors' contributions}

LM analyzed and interpreted the data, and drafted the manuscript. NW and YY interpreted the data and critically reviewed the manuscript. PV obtained funding for the study, conceptualized and designed the study, interpreted the data, and critically reviewed the manuscript. All authors read, edited and approved the final version. 


\section{Acknowledgements}

We thank all grade five students of the participated schools and their parents for their participation in the survey, the evaluation assistants and school health facilitators for their contribution during data collection and processing, and Megan Purcell and Connie Lu for leading the data collection, management, and validation. We also thank Erin Faught for assisting with the preparation of manuscript. The REAL Kids Alberta is funded by a contract with Alberta Health and the present study was further funded through a Canada Research Chair in Population Health, an Alberta Research Chair in Nutrition and Disease Prevention and an Alberta Innovates Health Solutions Scholarship to PJV. All interpretations and opinions in the present study are those of the authors.

\section{Author details}

${ }^{1}$ School of Public Health, University of Alberta, Population Health Intervention Research Unit, 3-50 University Terrace, 8303112 Street, Edmonton, AB T6G2T4, Canada. ${ }^{2}$ Agricultural, Food \& Nutritional Science, University of Alberta, 4-378 Edmonton Clinic Health Academy, 1140587 Avenue, Edmonton, AB T6G1C9, Canada. ${ }^{3}$ School of Public Health, University of Alberta, 3-299 Edmonton Clinic Health Academy, 1140587 Avenue, Edmonton, AB T6G1C9, Canada.

\section{Received: 16 July 2015 Accepted: 10 October 2015}

\section{Published online: 16 October 2015}

\section{References}

1. Statistics Canada. Vitamin D levels of Canadians, 2012 to 2013. http:// www.statcan.gc.ca/pub/82-625-x/2014001/article/14125-eng.htm. Accessed 28 Feb 2015.

2. Chao YS, Brunel L, Faris P, Veugelers PJ. Vitamin D status of Canadians employed in northern latitudes. Occup Med. 2013;63(7):485-93.

3. Rucker D, Allan JA, Fick GH, Hanley DA. Vitamin D insufficiency in a population of healthy western Canadians. Can Med Asoc J. 2002;166(12):1517-24.

4. Colapinto CK, Rossiter M, Khan MK, Kirk SF, Veugelers PJ. Obesity, lifestyle and socio-economic determinants of vitamin D intake: a population-based study of Canadian children. Can J Public Health. 2014;105(6):e418-24.

5. Newhook LA, Sloka S, Grant M, Randell E, Kovacs CS, Twells LK. Vitamin D insufficiency common in newborns, children and pregnant women living in Newfoundland and Labrador, Canada. Matern Child Nutr. 2009;5(2):186-91.

6. Wagner $\mathrm{CL}$, Greer FR. Prevention of rickets and vitamin D deficiency in infants, children, and adolescents. Pediatrics. 2008;122(5):1142-52.

7. Janz T, Pearson C. Health at a Glance: Vitamin D blood levels of Canadians. Ottawa: Statistics Canada. http://www.statcan.gc.ca/pub/82-624-x/2013001/ article/11727-eng.htm. Accessed 12 Aug 2014.

8. Vimaleswaran KS, Berry DJ, Lu C, Tikkanen E, Pilz S, Hiraki LT, et al. Causal relationship between obesity and vitamin D status: bi-directional Mendelian randomization analysis of multiple cohorts. PLOS Med. 2013;10:e1001383.

9. Tsiaras WG, Weinstock MA. Factors influencing vitamin D status. Acta Derm Venereol. 2011;91:115-24.

10. Health Canada. Food and drug regulations (C.R.C., c. 870). http://lawslois.justice.gc.ca/eng/regulations/C.R.C.\%2C_C._870/page-87.html\#h-74. Accessed 20 May 2015.

11. Vatanparast H, Calvo MS, Green TJ, Whiting SJ. Despite mandatory fortification of staple foods, vitamin D intakes of Canadian children and adults are inadequate. J Steroid Biochem Mol Biol. 2010;121(1):301-3.

12. Calvo MS, Whiting SJ, Barton CN. Vitamin D fortification in the United States and Canada: current status and data needs. Am J Clin Nutr. 2004;80(6 Suppl):1710-6.

13. Institute of Medicine. Dietary reference intakes for calcium and vitamin D. Washington: National Academies Press; 2011

14. Greene-Finestone LS, Berger CD, De Groh M, Hanley DA, Hidiroglou N, Sarafin K, et al. 25-Hydroxyvitamin D in Canadian adults: biological, environmental, and behavioral correlates. Osteoporos Int. 2011;22(5):1389-99.

15. Moore CE, Radcliffe JD, Liu Y. Vitamin D intakes of children differ by race/ ethnicity, sex, age, and income in the United States, 2007 to 2010. Nutr Res. 2014;34(6):499-506.

16. Sahota JK, Shaw N. Preventing vitamin D deficiency in children in the UK. Nurse Prescribing. 2014;12(12):596-602.

17. Health Canada. Vitamin D and calcium: updated dietary reference intakes vitamin D and calcium. Ontario: Health Canada. http://www.hc-sc.gc.ca/fnan/nutrition/vitamin/vita-d-eng.php. Accessed 15 Apr 2015.
18. Mori N, Kubota M, Hamada S, Nagai A. Prevalence and characterization of supplement use among healthy children and adolescents in an urban Japanese city. Health. 2011;3(3):135-40.

19. Ervin RB, Wright JD, Kennedy-Stephenson J. Use of dietary supplements in the United States, 1988-94. Vital Health Stat 11. 1999;244:i-iii. 1-14.

20. Sien YP, Sahril N, Mutalip MHA, Zaki NAM, Ghaffar SA. Determinants of dietary supplements use among adolescents in Malaysia. Asia Pac J Public Health. 2014;26(5):36S-43S.

21. Shaikh U, Byrd RS, Auinger P. Vitamin and mineral supplement use by children and adolescents in the 1999-2004 national health and nutrition examination survey: relationship with nutrition, food security, physical activity, and health care access. Arch Pediatr Adolesc Med. 2009;163(2):150-7.

22. Reaves L, Steffen LM, Dwyer JT, Webber LS, Lytle LA, Feldman HA, et al. Vitamin supplement intake is related to dietary intake and physical activity: the Child and Adolescent Trial for Cardiovascular Health (CATCH). J Am Diet Assoc. 2006;106(12):2018-23.

23. Foote JA, Murphy SP, Wilkens LR, Hankin JH, Henderson BE, Kolonel LN. Factors associated with dietary supplement use among healthy adults of five ethnicities the multiethnic cohort study. Am J Epidemiol. 2003;157(10):888-97.

24. Fennell D. Determinants of supplement usage. Prev Med. 2004;39(5):932-9.

25. Fung C, Kuhle S, Lu C, Purcell M, Schwartz M, Storey K, et al. From "best practice" to "next practice": the effectiveness of school-based health promotion in improving healthy eating and physical activity and preventing childhood obesity. Int J Behav Nutr Phys Act. 2012;9(1):27.

26. Willett W. Nutritional epidemiology. London: Oxford University Press; 2013. http://www.oxfordscholarship.com/view/10.1093/acprof:oso/ 9780199754038.001.0001/acprof-9780199754038. Accessed 23 Aug 2014.

27. Cole TJ, Bellizzi MC, Flegal KM, Dietz WH. Establishing a standard definition for child overweight and obesity worldwide: international survey. Br Med J. 2000;320(7244):1240-5.

28. Janz KF, Lutuchy EM, Wenthe P, Levy SM. Measuring activity in children and adolescents using self-report: PAQ-C and PAQ-A. Med Sci Sports Exerc. 2008:40(4):767-72.

29. Kim S, Haines PS, Siega-Riz AM, Popkin BM. The Diet Quality Index-International (DQI-I) provides an effective tool for cross-national comparison of diet quality as illustrated by China and the United States. J Nutr. 2003;133(11):3476-84.

30. Rockett HR, Breitenbach M, Frazier AL, Witschi J, Wolf AM, Field AE, et al. Validation of a youth/adolescent food frequency questionnaire. Prev Med. 1997;26(6):808-16.

31. Canadian Nutrient File (CNF). Health Canada. 2010. http://www.hc-sc.gc.ca/ fn-an/nutrition/fiche-nutri-data/cnf_downloads-telechargement_fceneng.php. Accessed 09 Dec 2014.

32. Whiting SJ, Langlois KA, Vatanparast H, Greene-Finestone LS. The vitamin D status of Canadians relative to the 2011 dietary reference intakes: an examination in children and adults with and without supplement use. Am J Clin Nutr. 2011;94:128-35.

33. Hollis BW. Circulating 25-hydroxyvitamin D levels indicative of vitamin D sufficiency: implications for establishing a new effective dietary intake recommendation for vitamin D. J Nutr. 2005;135(2):317-22.

34. Munasinghe LL, Willows N, Yuan Y, Veugelers PJ. Dietary reference intakes for vitamin D based on the revised 2010 dietary guidelines are not being met by children in Alberta, Canada. Nutr Res. 2015 (in press). http:// dx.doi.org/10.1016/j.nutres.2015.07.006.

35. Valtueña J, Gracia-Marco L, Vicente-Rodriguez G, González-Gross M, Huybrechts I, Rey-López JP, et al. Vitamin D status and physical activity interact to improve bone mass in adolescents. The HELENA study. Osteoporos Int. 2012:23(8):2227-37.

36. Ekwaru JP, Zwicker JD, Holick MF, Giovannucci E, Veugelers PJ. The importance of body weight for the dose response relationship of oral vitamin D supplementation and serum 25-Hydroxyvitamin D in healthy volunteers. PLoS One. 2014;9(11), e111265. 